\section{Hábito y conflicto en Hegel}

Habit and Conflict in Hegel

\section{Félix Duque}

\section{RESUMEN}

Nada más habitual que el hábito. Y, sin embargo, de seguir a Aristóteles, no existirían virtudes entre nosotros, o sea: aptitudes y habilidades que acaban por configurar la existencia humana. En este ensayo se examina el desarrollo dialéctico del hábito en Hegel, desde la Antropología hasta la Eticidad (Filosofía del Derecho): en el plano individual, desde el estado fetal y el desvarío en el alma sentiente hasta el autosentimiento de sí y el nacimiento del Yo; en el plano colectivo, se atiende más bien a la génesis del hábito y sus fautores: las corporaciones, las instituciones estatales y la opinión pública, hasta desembocar en el extraño estadio del hábito como deshabituación de todo hábito, en el fenómeno de la guerra. Se pone así de relieve el modo en que el hábito es el modo crucial de ser entre la individualidad animal y el cuerpo sociopolítico como aparato mecánico que promete vida y amenaza muerte.

Palabras clave: Naturaleza; Espíritu; Mecanismo; Autosentimiento; Sí mismo (Selbst); Habitar

\section{ABSTRACT}

Nothing is more habitual than habit. And yet, if we were to follow Aristotle, without it there would be no virtues between us, that is to say: aptitudes and abilities that end up shaping human existence. This essay examines the dialectical development of habitus in Hegel, from Anthropology to Ethicism (Philosophy of Right): on the individual level, from the fetal state and the derangement in the sentient soul to self-sentience and the birth of the ego; on the collective level, it is more concerned with the genesis of habitus and its authors: Corporations, state institutions and public opinion, until we reach the strange stage of habit as the dishabituation of all habit, in the phenomenon of war. It thus highlights the way in which habitus is the crucial mode of being between animal individuality and the sociopolitical body as a mechanical apparatus that promises life and threatens death.

Keywords: Nature; Spirit; Mechanism; Self-feeling; Itself (Selbst); Habit
INFORMACIÓN

http://doi.org/10.46652/resistances.v2i4.74 ISSN 2737-6222 |

Vol. 2 No. 4, 2021, e21074

Quito, Ecuador

Enviado: noviembre 02, 2021 Aceptado: diciembre 30, 2021

Publicado: enero 10, 2022

Publicación continua

Sección dossier | Peer Reviewed

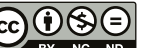

OPEn ACCEss

AUTOR

Félix Duque

Universidad Autónoma de Madrid - España felix.duque@uam.es

Conflicto de intereses

El autor declara que no existe conflicto de interés posible.

Financiamiento

No existió asistencia financiera de partes externas al presente artículo.

Agradecimiento

Quiero agradecer a Oled Balaban, Miguel Giusti, Nuria Sánchez Madrid, Marco Sgarbi y Valerio Rocco la atención con que han leído este artículo y las valiosas sugerencias que me han enviado; aquellas que, por premura de plazos, no he podido recoger, servirán -espero- para ulteriores profundizaciones sobre el tema.

Nota

N/A
PUBLISHER 
Enrico Berti

in memoriam.

Maestro di color

che sanno di Aristotele

A la segunda naturaleza hay que pelearla para sacarla de ese estado hipopotámico de tranquilidad con el ser bajo el calor agradable del agua estancada

Oded Balaban

No sin audacia, por no hablar de atrevimiento, cabría definir quizá la empresa hegeliana como un ensayo de explicitación del empeño humano por habitar decentemente la tierra en la Modernidad. El adverbio de modo subrayado remite a decens; $y$, de ahí, al verbo en forma impersonal decet: es apropiado o conveniente (p.e. en Cicerón, De Officiis 1, XXXI, 113: id enim maxime quemque decet, quod est cuiusque maxime suum; en efecto, nada hay más conveniente para cada uno que aquello que le es propio en grado sumo). Ahora bien, según Hegel, lo que más le conviene en propiedad al hombre es desde luego el pensar y su puesta en práctica; es por ese rasgo esencial por lo que se distingue de los animales (también ellos, habitantes de tierra: el pensar es lo más propio del hombre, aquello por lo que se diferencia del ganado, mientras que tener sensaciones es común a ambos: Enz. § 400, Anm.; TWA 10, 99); y ello, hasta el punto de que: todo lo humano lo es, y lo es únicamente, cuando viene puesto en obra por el pensar (Enz. § 2; TWA 8, 42).

Pero, ¿qué tiene ver el pensar con el habitar, y más precisamente, con habitar la tierra? Al respecto, cuando examina el sentido de la apercepción pura -el foco supremo subjetivo del pensar en Kant-, y que Hegel entiende significativamente como la actividad de hacer mío [lo existente], señala Hegel: El esfuerzo humano está en general dirigido a conocer el mundo, a apropiarse de él y a dominarlo [atiéndase a esta supuestamente evidente equiparación, F.D.], de modo que, al final, la realidad del mundo ha de quedar por así decir exprimida (o triturada: zerquetschen), es decir: idealizada (Enz. § 42, Zus.; TWA 8, 118). Si por Realität del mundo entendemos la naturaleza, entonces es obvio que el pensar, en su respecto práctico, no consiste en otra cosa que en elevar esa presunta realidad (vista como algo consistente, con sentido propio) al nivel ideal, lo cual exige, para empezar, que la naturaleza sea exprimida como si de una naranja se tratara, para extraer de ella el zumo lógico, el cual, vuelto y revuelto contra todo lo natural mediante la libre voluntad, acabe por convertir esa naturaleza, trabajada y reelaborada, en una segunda naturaleza (Rechtsphil. § 4; TWA 7, 46; Testa 2009, Novakovic 2017; Khurana 2018). Si esto es así, cabría preguntarse, por cierto, a dónde ha ido a parar la pulpa del mundo, desechada, eso que antes he denominado tierra, despreciada ahora como lo que sobra de la primera naturaleza tras sufrir tamaña reelaboración, y cuyas consecuencias sufre hoy la entera humanidad, tanto a nivel global (por el catastrófico empeoramiento del clima) como microscópico (en el caso de la 
devastadora pandemia del SARS-CoV-2), en un estado por demás de tensión bélica permanente entre las grandes potencias. Sólo al final indicaré sucintamente algo al respecto. Y no sé si saldrá del todo bien parada esa decencia al inicio evocada.

Por lo pronto, y por lo que hace al problema de habitar esta tierra (más que de habitar en ella, como si a ella no perteneciéramos): una tierra cada vez más transformada en mera habitación humana, cabe adelantar dos puntos clave. Primero, que, en cuanto habitante de una habitación que el propio hombre se ha dispuesto a partir de tierra, y contra ella (pues para habitarla es preciso primero colonizarla en grado sumo, como si el hombre fuera del todo ajeno a ella), es evidente que el comportamiento humano para con la naturaleza ha de ser práctico, habiéndoselas con ella como si ésta fuera un ser inmediato y exterior, de la misma manera que el hombre se las ha consigo mismo como un individuo exterior $\mathrm{y}$, por ende, sensible, pero que, de este modo, no deja de conducirse, y con derecho, como fin frente a los objetos naturales (Enz. § 245; TWA 9, 13). En este punto inicial (se trata de las primeras frases de la Filosofía de la naturaleza), todavía estamos lejos de una plena idealización del mundo. Sea como fuere, lo que Hegel da por sabido es que tal individuo (el cada uno ciceroniano) obra de ese modo mit Recht. Algo que sólo más tarde será explicitado.

En cuanto al segundo punto, cabe preguntarse por el modo en que esos objetos naturales, convertidos ahora en productos por la praxis humana, son tratados y considerados en la filosofía hegeliana. Al respecto, la respuesta es tan inmediata como contundente: a la filosofía, tanto esas cosas como los hombres que se ocupan de ellas no le importan absolutamente nada. Todo eso se lo deja Hegel, displicente, al sentido común. Ello, no obstante, reconoce que ese gesunden Menschenverstand (sano entendimiento humano) es gran ventaja para un hombre (eines Menschen); de nuevo, se insiste aquí en este carácter individual e inmediato. Pero el sentido común tiene sus límites: En la filosofía -sentencia Hegel- no basta con tenerlo, pues ella abandona más bien todos esos puntos de apoyo, esas costumbres (Gewohnheiten), las habituales visiones que se tienen del mundo, a las cuales se atiene el sentido común en su vida y en su pensamiento: su concepto de lo verdadero, del derecho, de Dios. Y, por si fuera poco, añade al margen: Los Estados van siempre contra el sano entendimiento humano. (Konzept der Rede beim Antritt des philosophischen Lehramtes an der Universität Berlin. Einleitung zur Enzyklopädie-Vorlesung, 22. Okt. 1818. TWA 10, 415s.). Ahora bien, si nos atenemos a esta tajante expulsión del ámbito filosófico respecto a las cosas habituales, es obvio que debemos dar por terminado este ensayo -dedicado al hábito y su carácter conflictivo- apenas comenzado.

Quizá cabría resolver este enojoso problema acogiéndonos a algo que podríamos tildar de mito del origen, como hace por ejemplo Martin Heidegger:

...aquello que a nosotros nos parece natural no es presumiblemente sino lo habitual de una larga habituación (das Gewöhnliche einer langen Gewohnheit) que ha olvidado lo inhabitual del que ella surgió. Hubo sin embargo una vez en la que eso inhabitual asaltó al hombre como algo extraño (ein Befremdendes) que llevó a asombrarse al pensar (UKw, p. 9). 
Por cierto, el propio Hegel estaría seguramente de acuerdo en eso de la larga habituación que ha convertido algo en habitual y, por ende, en natural, pero no lo estaría tanto con la afirmación ulterior, de clara ascendencia platónico-aristotélica (recuérdese el thaumázein del Teeteto,155C-D; y de la Metafísica, 982b11ss.), y que Heidegger interpreta pro domo sua, según la cual lo habitual habría surgido de algo Ungewohntes y Befremdendes (y además, una vez y sólo una vez: einst, in illo tempore). Pero Hegel no cree en esa mítica trascendencia (o, si se quiere, en ese trascendentalismo propio de la diferencia óntico-ontológica). No hay ningún origen absoluto, ni tampoco nada absolutamente inmediato y primero, como una donación primigenia (por no hablar de revelación u Offenbarung), ahora olvidada. El sano entendimiento humano bien pude admirarse de cosas que escapan a sus entendederas; cosas que, por cierto, al menos al sobrio Aristóteles no le asombran en absoluto; lo que él tiene más bien en cuenta es que ahora, tras la pacificación lograda por Alejandro, ha llegado el momento de ponerse en serio a pensar; algo mismo les decía Hegel a sus estudiantes en 1818, a saber: que, tras las guerras de liberación contra Napoleón, ahora había llegado el momento de dedicarse decentemente a lo que a cada uno de ellos -y de nosotros- le es más propio y conveniente: pensar.

Pero entonces, ¿de dónde procede lo habitual? Respuesta nada estupefaciente (por decirlo con expresión cara a Ortega): procede del desgaste y obsolescencia de una habituación que ha dejado de ser decente, es decir conveniente y apropiada para la existencia humana, y que ha sido sustituida -de grado o por fuerza- por otra habituación (por otro modo de habitar) que engloba o asume (hebt auf) un hábito anterior, llegándose incluso -concesión a Heidegger-al hecho de olvidar ese hábito periclitado. Siempre es ya de siempre demasiado tarde para hablar filosóficamente de un origen, de un comienzo primero. Sencillamente, un hábito procede de otro hábito, y así ad infinitum (aunque ello -al nivel del entendimiento- sea un infinito malo, mientras no se aclare qué sea eso de hábito). Como veremos luego con algo más de detenimiento, no hay que dejarse engañar por la ordenación enciclopédica, como si los temas en ella examinados surgieran cronológicamente uno después de otro. Se ha dicho muchas veces, y con razón, que Hegel es el pensador de la historia. Naturalmente, esto es verdad... cuando se trata del estudio de la Historia Universal (lo cual no quiere decir tampoco -dicho sea de paso- que las categorías lógicas subyacentes a ese estudio hayan ido surgiendo en el tiempo a la vez que los acontecimientos históricos a los que convienen).

Claro está que, si esto es así, entonces el problema de qué hacer con las cosas habituales y con los hábitos que las producen parece agravarse aún más. Así que a punto está uno de recordar aquello tan cristiano: Deja que los muertos entierren a sus muertos (Mateo 8,22), y abandonar el asunto por imposible. Sólo que una cosa es ocuparse de asuntos, sucesos o cosas existentes (en este caso: habituales), y otra muy distinta examinar críticamente qué significa el hábito, cuáles son sus características, qué consecuencias tiene la habituación para la vida cotidiana -y aún para más altas cuestiones políticas- y cuál es el locus logicus por el que esa habituación alcanza validez, alcance y sentido. La respuesta que Hegel daría a Heidegger, creo yo, sería que no hay lugar alguno donde excavar extrañezas mediante un salto al origen (eso significaría literalmente Ur-Sprung, como se indica en el curso Der Satz vom Grund). La filosofía no estudia las cosas habituales (para eso están el sano sentido común y, más refinadamente, las ciencias al 
ras del entendimiento, cuyo contenido, por demás, reconoce y utiliza la filosofía, reconociendo lo universal que hay en ellas: cf. Enz. § 9, Anm. TWA 8, 52). Ello no obsta sin embargo para dejar sentado que: En general, la filosofía tiene, en cuanto filosofía, categorías distintas a las de la conciencia habitual; el modo de formarse (Bildung) depende tan sólo de la diferenciación de categorías (Enz. § 26, Zus. TWA 9, 20). Y es que, en lo habitual, Heidegger cree entrever (como de soslayo: durch einen Wink) lo inaudito de su origen. Hegel, por su parte, piensa lo habitual desde un enfoque inaudito; si se quiere: lo asombroso no es el origen, sino el pensamiento -y más, el filosófico-, que no tiene ternura alguna para con las cosas mundanas (cf. Enz. § 48. TWA 8, 126). La filosofía hegeliana comprende y comprehende, concibe en suma aquello que el entendimiento se limita a entender, como es natural, asumiendo de esta manera las cosas sólo entendidas.

¿Y qué cosa hay más natural que el hábito? (Para nosotros, hombres, más natural que la propia naturaleza, a la cual estamos cada vez menos habituados). Al respecto, una breve exploración etimológica podrá servir quizá de introducción a la problemática. En latín, habitus es el participio pasado en masculino de habeor, la voz pasiva de habeō. Significa pues: algo que ha sido retenido, mantenido y, en definitiva, poseído. Por su parte, el verbo habitō es un frecuentativo de habeō. Así, el habitar es el resultado de la repetición frecuente de aquello que uno tiene y posee, de aquello con lo que uno se las ha. Por su parte, Gewohnheit (hábito, y mejor: habituación; en francés, más propiamente: habitude) es palabra compuesta por el prefijo ge-, con el que se forma el participio pasado de los verbos, denotando lo sedimentado por frecuentación y repetición de acciones; la raíz wohn-, de wohnen (habitar), un verbo emparentado con Wunsch (deseo) y gewinnen (lograr, ganar); por ende, y como resultado: estar satisfecho, sich gewöhnen: habituarse a estar en un sitio. Y el sufijo -heit determina cualitativamente la raíz. Así que, en alemán, lo denotado por Gewohnheit podría describirse como la cualidad de haber habitado; y, se entiende: de seguir haciéndolo. Por fin, el término griego correspondiente: héxis (manera de ser, temperamento, hábito), procede del verbo échō, equivalente semánticamente al latín habeo. Es importante señalar que una de las formas primitivas de échō es schếsō (cf. Dictioonnaire, sub voce), cuyo sustantivo es schếma: disposición exterior, figura (en Hegel, sobre todo en la esfera lógica, traslada al efecto, del griego al alemán: Beschaffenheit; en la Antropología, en cambio, el hábito puede ser entendido como una disposición tal que, al potenciar mediante el ejercicio el dispositivo (Anlage) adquirido consciente o inconscientemente, se convierte en un nuevo y más alto dispositivo: la costumbre o Sitte; de ahí la Sittlichkeit, a la que está dedicada la tercera parte de la Filosofía del Derecho). Por su parte, en Aristóteles, el ejercicio reiterado, consciente y deliberado de las héxeis conduce a las virtudes dianoéticas, como la téchnē y la phrónēsis. En cuanto tal, el hábito se aproxima potencialmente a la felicidad, pues el placer (hedonế) es la cumplimentación de la enérgeia. Por eso, mientras que a la felicidad hay que rendirle honores como a algo divino, en cambio, por lo que hace al carácter virtuoso, en cuanto trabazón o ensamblaje estabilizado de héxeis, aun siendo igualmente merecedor de alabanza, lo es en menor grado, dado que se trata tan sólo de un logro potencial, en cuanto esfuerzo que tiende a la satisfacción de un deseo (como en el wohnen alemán; cf. Eth. Nic. I, 12; 1101b-1102a). 
De este breve repaso etimológico podemos extraer algunas conclusiones, relevantes para nuestra temática. En primer lugar, parece que el hábito es una forma privilegiada del haber, de manera que habremos de atender primero a las resonancias de este verbo de clara composición y compostura dialécticos, pues que remite de un lado a una actividad por la cual no sólo se distingue el tenedor como poseedor de aquello que él tiene y mantiene (es decir, de algo que no existiría sin él, por cuenta propia), sino que se identifica consigo mismo solamente al negar que eso que él tiene sea su propio ser; al contrario, ese su ser se da tan sólo como referencia simple a sí mismo en la negación de la consistencia de aquello que él tiene (y que aparece, así, como un ser prestado, diríamos). Pero, al mismo tiempo que él pone esa su posesión como sus haberes (tal era el sentido primero, por cierto, de la ousía griega), presupone aquélla como su manifestación, y más: como su existencia externa, por la cual y sólo por la cual el tenedor se conoce a sí mismo; demasiado tarde, pues, como para poder conocerse antes de esas sus posesiones. Por eso, el habérselas uno consigo mismo, el tener sentimiento de sí, viene de resultas del habérselas con las cosas que a mí me pasan. De ahí el sentido pasivo de esos haberes, los cuales, por ende, pasan a ser inmediatamente cosa del pasado.

El primer y más inferior nivel en el que aparece el haber, en cuanto distinto al ser, es el de la cosa y sus propiedades (siendo su lugar lógico el de la ostensión inmediata de la Existenz, en cuanto contra distinta de la esencia o Wesen, mientras que en el plano filosófico-natural corresponde a la química, sensu lato). Es obvio que la cosa no es sus propiedades, sino que las tiene. Pero ella misma no es sino el cruce negativo de constar de propiedades, por las que ella se manifiesta y en las que existe (lado activo del haber o tener: unum e pluribus) y de estar compuesta o consistir de materias o estofas (lado pasivo: e pluribus unum), que no tienen existencia propia, fuera de ese dar consistencia a la cosa (me muevo aquí, claro está, dentro de las coordinadas de las concepciones químicas, dinamicistas y antiatomistas, de Hegel). Sea como fuere, lo relevante aquí es señalar que este tener o haber no es ajeno a sus propiedades ni se disuelve en sus componentes, sino que se las ha sólo en esos haberes. Como dice Hegel: Pero la cosa es la reflexión-dentro-de-sí, en cuanto identidad diferente de la diferencia, o sea de sus determinaciones. Ahora bien, que Hegel -como de costumbre- no está interesado tanto en la cosa misma cuanto en su consideración de ésta como algo todavía abstracto y no bien definido de aquello de lo cual es ella indicio, lo muestra la continuación del pasaje: El haber (o tener: Das Haben) viene usado en muchos idiomas para caracterizar el pasado: y con razón, pues el pasado es el ser [como] asumido (das aufgehobene Sein) y el espíritu la reflexión de ese pasado dentro de sí (deren Reflexion-in-sich); una reflexión en la cual solamente sigue teniendo consistencia ese pasado (Enz. § 125, Anm. TWA 8, 256).

Esa al punto sorprendente aparición del espíritu en este contexto muestra ya lo insuficiente de esa primera reflexión, inmediata, como se muestra, en la esfera precisamente del espíritu, en la definición y tratamiento del alma como si ésta fuera una sustancia, una cosa simple, inmaterial, inmortal, etc., como si estas propiedades fueran algo fijo, estático y quieto. De manera que la introducción, o mejor irrupción -literalmente intempestiva- del verbo haber para explicar en qué consiste ser cosa, rompe esa quietud y deja ver la contradicción en la que caen de consuno el entendimiento natural y la naturaleza, así entendida. 
Así se deja ver ya el difícil y complejo desarrollo dialéctico por el que, limitándonos tan sólo a la Antropología -en cuyo centro se alza justamente el hábito-, el alma (un término en el que resuena el viejo sentido griego de psyché) es el principio activo de algo distinto a ella, pero en lo cual únicamente tiene ella sensaciones que, para empezar, parece limitarse a sentir: empfinden, en el sentido de ser hallada-pero sólo en sí o para nosotros- en lo adverso -señalado en el prefijo emp; latín y griego: anti-. Como si se tratara, en esta primera inmediatez, de un yo simple: un pozo carente de determinación, en el cual todo está conservado, sin existir (Enz. § 403, Anm.; TWA 10, 122). Y, sin embargo, eso que ella siente no deja de ser sensaciones suyas; por ellas y en ellas existe, aunque ellas de suyo no existan (recuérdese la dialéctica de la cosa y sus propiedades).

Por cierto, el nivel más alto de esa inmediatez sólo sentida viene ilustrado por Hegel con el ejemplo del estado del feto humano en el útero materno. El nivel intermedio de esta relación -de sabor tan griego- viene resaltado por el filósofo cuando señala que ella no se establece a nivel corporal ni tampoco espiritual, sino psíquico: una relación del alma. Alma, la psyché, es pues el lugar en el que cuerpo y espíritu, sin llegar a confundirse uno en el otro, se entremezclan en aquello que, para el ámbito paleocristiano, denominaba Tertuliano: anima carnalis (cf. Tertuliano, 1956; c. 13). Aquí el cuerpo (Körper) se torna cuerpo vivo (Leib) y el espíritu se hace encarnamiento. Dicho sea de paso, me parece preferible traducir así la Verleiblichung hegeliana (cf. Enz. § 401, Zus.; TWA 10, 112) por encarnamiento (ingl.: embodiment); o bien, en sentido activo, como encarnación, en lugar de incorporación. Y es que, como señala Drew Leder, en un sentido híbrido en el que se conjugan fructíferamente la fenomenología de Husserl y de Meraleau-Ponty con la neurociencia:

El término 'incorporación' parece implicar un proceso de absorción que operase
de forma unitlateral. Mediante una ósmosis fenomenológica, el cuerpo entraña
nuevas habilidades, su propia historia temporal, y hasta herramientas, aun cuando
están sigan existiendo separadas espacialmente. Sin embargo, la incorporación
es también el resultado de una rica dialéctica en la cual el mundo transforma mi
cuerpo, al igual que mi cuerpo transforma el mundo (Leder, 1990, p. 34).

En el tema que estamos ahora considerando, todavía no hemos llegado a ese nivel (que sólo se logrará en el paso final de la Psicología a la esfera del Espíritu objetivo); porque, dentro del cuerpo de la madre, el neonato no deja de ser un individuo, a pesar de que haya una sola unidad psíquica, inseparada, porque aquél no puede ofrecer resistencia alguna al influjo (en sentido literal: algo que fluye, entrando en otro cuerpo) de la madre; por eso la denomina Hegel: Genius, utilizando de nuevo -como en la psyché- un arcaismo, como si quisiera desplazar así las claras resonancias a la posesión religiosa: sagrada o diabólica (Enz. § 405, Anm.; TWA 10, 125). Es interesante señalar que, en las lecciones del curso 1827/28, utiliza Hegel al respecto una expresión que, a su vez, remite al Kant de Idea de una historia universal: Anlage o Naturanlage (cf. Idee, espec. tesis 1, 3, 4, 6 y 9; Ak. VIII, 15-32). La expresión puede traducirse como dispositivo (con intencionada remisión por mi parte al dispositif foucaultiano): el lado pasivo del encarnamiento psicofísico (en Foucault, activado sociopolíticamente). Así también, en Hegel: El niño en el cuerpo de la 
madre (Mutterleibe) tiene el dispositivo (Anlage) propio del ser humano; ya es hombre, pero sólo en sí, sin ser todavía autónomo (selbständig) (VPhSG; G.W. 25.2, 674). Y de un modo ciertamente significativo -para el respecto activo, el heredado de los padres-, el filósofo utiliza disposiciones (Dispositionen; VPhSG; G.W. 25.2, p. 675).

Cubriendo ambos respectos, pasivo y activo, el genio (en griego: daímōn) es entonces: la totalidad del espíritu afectado de mismidad (selbstische) (Enz. § 405, Anm.; TWA 10, 125). Al contrario del indidivuo que afecta, el niño afectado no es todavía, pues, Selbst (sí mismo). Incluso cabría hablar -llevando al extremo el fenómeno de la posesión- de infección de por vida, dado que los dispositivos heredados seguirán siendo eficaces durante toda la existencia humana. No se trata en efecto de nada compartido (mitgeteilt), sino de lo recibido originariamente: dispositivos de la enfermedad (Krankheits-Anlagen: predisposiciones), así como los demás dispositivos: figura, modo de sentir, carácter, talento, idiosincrasia, etc. (ib. 10, 126). Pero esa mismidad no es compartida: se extiende por entero sobre la madre y el feto, sólo que -como de costumbre en Hegel- es el lado más arrimado al espíritu el que prevalece. Esa mismidad es como un manto protector (recuérdense las pinturas medievales de la Madonna); sólo que, al mismo tiempo, el niño: esa individualidad [sólo] sentida, está poseída, completamente llena (ausgefüllt) de esta individualidad íntegra (Zus.; 10, 127), como si de una oquedad o vasija se tratase (invirtiendo así las tornas: mientras que, físicamente, la madre viene metonímicamente identificada con el seno o útero, psíquicamente es ella la plena y plenificadora, llenando al feto, todavía espiritualmente hueco, con el líquido psíquico de su alma carnal. Por cierto, al final del desarrollo del Espíritu objetivo, y con evidentes resonancias paulinas, dirá el filósofo, recopilando todo el recorrido, que la necesidad [lógica], la naturaleza y la historia no hacen otra cosa que servir a la revelación del Espíritu, siendo los vasos (Gefässe) de su gloria (Enz. § 552; TWA 10, 353; cf. S. Pablo, 2 Corintios 4, 7).

Volviendo al punto ahora examinado, mientras que la madre no deja de ser una sustancialidad subjetiva, en cambio el niño: está puesto como individuo sólo de manera exterior. De este modo: Lo sustancial del genio es la entera totalidad de la existencia, de la vida y del carácter. Por ende, Hegel se desprende por así decir de los aromas cristianos para regresar a la antigüedad griega, donde incluso la madre más alta, la pólis, plenifica cuerpo y espíritu de sus hijos, marcados como están por su status y por el lugar y modo de nacimiento.

Por ello, cuando Hegel se refiere al genius (el cual, aun calificando ante todo a la madre, se extiende también a los fenómenos del llamado magnetismo animal: el hipnotismo), es difícil no recordar al respecto el célebre apotegma heraclíteo: éthos anthrōpōi daímōn (DK22B119). Kranz traduce: Para el hombre su sentido [entiendo: el sentido de su vida] es su dios. (Dem Menschen ist seinen Sinn sein Gott: DK, p. 78). Otras versiones vierten daímōn por destino (p.e. Ruth Holtz (2017): El carácter es el destino del hombre). En ambos casos se vierte la frase (ciertamente críptica) de modo correcto, pero sin agotar su sentido. Para empezar, êthos no es solamente el sentido [de la vida] ni tampoco su destino: eso sería en todo caso la manifestación o exteriorización -fisiológica o temporal- del éthos, el cual significa más bien: habitude (como primera acepción; 
también: usage, demeure; cf. Dictionnaire, sub voce). O sea, precisamente: hábito y, por extensión: carácter (lo adquirido a través de la habituación), aunque, figuradamente, bien valdría hablar aquí también de morada (al cabo, la libertad es en Hegel un estar en casa -bei sich sein- dentro de lo otro). Por cierto, de éthos deriva el adjetivo: éthikós (moral, concerniente a las costumbres). Así que cabría traducir, con mayor precisión: Para el hombre, el hábito es su genius (como si dijéramos: en y por el hábito, el hombre se halla en su propia casa). Es interesante añadir también (por su relevancia ulterior), que ya en griego se confundían éthos y éthos (propiamente: usanza, institución); del verbo desusado: éthō, el cual perdura todavía -siempre según el Dictionnaire- en el participio sustantivado: tò eiōthós (lo acostumbrado, habitual), así como en: hoí eiōthotes (los amigos y conocidos: Dictionnaire, sub voce: eíotha).

De esa transición fácil (por decirlo con Hume) puede surgir sin embargo una capciosa derivación de éthos (entendido como carácter) a partir del éthos (en cuanto usanza, al modo tradicional, antiguo y rural, o como institución: en ambos casos, el hábito surge pasivamente, a partir de una posesión). Como si dijéramos: son la costumbre ancestral o las instituciones sociopolíticas las que forjan la morada en general (la sangre y la tierra, la madre patria) y el carácter en particular del hombre; por ellas y a ellas, éste ha de ofrecer pensamiento, acción e incluso la propia vida. Esta inversión enciclopédica (hacer del hábito -algo propio del sentimiento de sí- una inmediatez sentida, característica de la mismidad) acompaña como una sombra todo el desarrollo de la noción de hábito (y no sólo en Hegel, claro está).

Por fortuna, en Hegel es ésta tan sólo una primera etapa en la evolución del alma sentiente. La segunda implica ya un cierto equilibrio entre la sensación interiorizada (el sentimiento) y el alma, que desde la mismidad vuelve en sí misma. Para nosotros (y sólo para nosotros), se trata ya del nacimiento del yo. En el plano fisiológico, cabría hablar al respecto de sensitividad: algo que, por cierto, no se siente hasta haber reflexionado, interiorizado-y-sentido esas sensaciones; en español, resulta difícil expresar verbalmente esa diferencia, ya que tenemos el mismo verbo: sentir, para empfinden (sentir algo) y para fühlen: sentirse uno a sí mismo al sentir eso; y aquí, de nuevo, aparece el haben (haber o tener): la incitación primera se torna en excitación (en alemán: Irritabilität). Como señala Hegel: no se dice desde luego sensación (Empfindung) del derecho, de sí mismo etc., sino sentimiento (Gefühl) del derecho, autosentimiento (Selbsgefühl) (Enz. § 402, Anm.; TWA 10, 117). Este viaje de descubrimiento de mí mismo culmina en el total desprendimiento de esa exterioridad mía que siento -y con razón- como algo natural, para distanciarla de mí como una cosa extraña (desustanciándola y descosificándola, si decirse pudiera) precisamente al entrañarla como representaciones de mi conciencia, pasando de este modo de la Antropología a la Fenomenología. Y en ella, en fin, la conciencia da razón de sí en una abstracción total que se torna al punto en la más alta contradicción: el Yo. Llegada a esa meta, el alma ingresa en la libertad abstracta del Yo y se convierte así en conciencia (Enz. § 402, Zus.; TWA 10, 122).

También aquí encontramos el apoyo lógico para comprender esa seipseidad (ser igual a mí mismo al negar -y por negar- todo lo demás en cuanto distinto de mí) cuando Hegel aborda -como no podía ser menos- la contradicción como doble reflexión quiasmática: la reflexión determinante 
resulta ser, al volver sobre sí, la determinación-de-reflexión. Y es que, como apunta Hegel: todo contenido, que, en cuanto tal, es siempre algo concreto (ein Konkretes) contiene dentro de sí no solamente determinaciones distintas (como en la cosa, F.D.), sino contrapuestas. Y al punto, añade: Así, p.e., nada hay más imposible que [esto: ser y decir que] yo soy (dass ich bin), pues Yo es a la vez simple (einfache) referencia a sí y referencia sin más (élechthin) a otro. (Enz. § 143, Zus.; TWA 8, 283). La contradicción se da en la famosa frase misma, si analizamos pronombre y verbo: yo no significa sino estar en referencia a otro: a cualquier ser, con tal de que no sea yo mismo; soy el resultado de negarlo todo, salvo ese pro-nombre; por su parte, soy remite al verbo ser, cuya primera definición (y, por ende, contradicción) es que ser es simple referencia a sí (Enz. § 112, Anm. TWA 8, 231). De manera que cada yo soy en particular equivale al cabo a Yo no soy (no hay algo así como el Yo en general). Por cierto, y dicho sea de paso, con esa imposibilidad (al ras del entendimiento) está dando Hegel una donosa contestación al Yo soy = Yo pienso cartesiano y kantiano, invirtiendo por completo paródicamente (en el sentido normal, y en el musical de parodia o contrafactum) aquello que Kant tiene justamente por lo imposible sin más (schlechthin), a saber, pensar que yo no soy: El pensamiento 'yo no soy' no puede existir en absoluto, pues si yo no soy [no existo] tampoco puedo ser consciente de que no soy [...] hablar en primera persona negando el sujeto mismo -de modo que éste se anule a sí mismo- es una contradicción. (Anthr. § 27. Ak. VII, 167).

Antes de llegar a ese punto, en la segunda etapa del alma en su viaje de descubrimiento hacia sí misma aparece ya el sentimiento de sí (Selbstgefühl o autosentimiento; cf. Enz. § 407 y sig.; TWA 10, 160-163), pero todavía lastrado por el hecho de que, aunque la objetividad sentida está ya interiorizada, puesta enfrente de la individualidad que tiene esos sentimientos, éstos se muestran como, por así decir, invasores del sí mismo o Selbst, de modo que éste pugna sin descanso por dominarlos, entrando así en episodios de lucidez y cayendo en otros en el pozo oscuro de sus sentimientos; aquí, ese contenido natural que está en el sí mismo que se deja arrastrar por él: por eso lo llama Hegel: selbstsüchtig; una mezcla irracional de Selbst (ser sí mismo, estar en casa propia) y de Sucht: (adicción, manía, o sea: estar poseído). Aquí, el contenido está todavía libre y campa por sus respetos, desatando pasiones o imaginaciones, esperanzas, amor u odio. Aquí también, el fiel luterano se revela en toda su fuerza: se trata -dice- del genio malvado del hombre, dominante en la locura (Verrückhtheit: literalmente, desplazamiento, desvarío, F.D.); algo que se enfrenta y contradice a lo mejor y más razonable (Verständige) que existe también en el hombre, de modo que tal estado de ánimo provoca en él desarreglo y desgracia (Enz. § 408, Anm.; TWA 10, 162; cf. Medea en Ovidio, Metamorph. VII, 20s.: video meliora proboque / deteriora sequor; y también S. Pablo, Romanos 7, 15 y 19).

En este respecto, puede ser bien ilustrativa la frecuencia con la que utiliza Hegel el pronombre demostrativo selbst, o bien sustantivado como das Selbst, correspondiente a los estadios segundo y tercero del alma, así como el lugar enciclopédico en el que se encuentra esta expresión, en la que se anticipa ya para nosotros el yo. En la Ciencia de la lógica (tanto en la editio maior como en la minor), y como cabía esperar -pues para eso expone ella el Sistema de la razón pura-, no aparece ni una sola vez. En la Filosofía del espíritu, diez veces: seis de ellas, en la Antropología. Y al final del 
Espíritu objetivo, como propiamente das Selbst, sólo una vez: se trata del Estado, entendido como individualidad libre y racional: el suelo (Boden) de la existencia libre de la sustancia universal, el Sí mismo del espíritu pensante (Enz. §552, Anm.; TWA 10, 362). Ahora bien, para evitar todo delirio protofascista al estilo de Blut und Boden, Hegel señala poco después que el Estado presenta en la realidad efectiva la unilateralidad, propia de la Idea en sí, [sólo] conforme a verdad (wahrhafte), como corrupción (Verdorbenheit: echarse a perder; 10, 363).

En cambio, nada más natural y postlógico (aunque al entendimiento le resulte sorprendente) que el hecho de que sea en la Filosofía de la naturaleza donde con mayor frecuencia se emplea la expresión y sus derivados: 33 veces. Por el contrario, y para apreciar siquiera sea cuantitativamente hasta qué punto se ha separado Hegel del Selbst de la Fenomenología, baste decir que ese pronombre sustantivado aparece allí 119 veces, entendiendo das Selbst, p.e., como la transformación del ser-ahí objetual de la esencia en un ser-ahí que tiene conciencia de sí mismo como siendo uno con la esencia (Phä. G.W. 9, 384).

Volviendo a la Enciclopedia, cabe decir que, al igual que en el estadio lógico-esencial de la cosa y sus propiedades encontramos por vez primera el desequilibrio entre haber (y tener) y ser (para ventaja de lo primero), ahora es en la esfera científico-natural donde lo orgánico pugna por apoderarse, por tener y controlar la violencia externa, interiorizándola como una resonancia y un calentamiento. Aunque este fenómeno se presenta primero en la repulsión, reflexionada como algo interno: el tono y el calor [es] en lo orgánico donde el Sí mismo se mantiene dentro de sí y se posee como algo ideal (als Ideelles) (Enz. § 303, Zus.; TWA 9, 186). Ulteriormente, como era de esperar, es en el proceso de autoconservación (Selbsterhaltungsprozess) donde se logra el Sí mismo, saturándose y llegando al sentimiento de sí (Selbstgefühl) (Enz. § 344, Zus.; TWA 9, 374). Pero es en el examen del Organismo animal donde encontramos la característica predominante del Sí mismo, a saber, que: el animal refrena [hemmt, inhibe, F.D.] su referencia a otro; él es el Sí mismo que es para Sí mismo: la unidad existente de los extremos diferenciados que atraviesa a ambos (Enz. §350, Zus; TWA 9, 430). Y es aquí también donde encontramos en fin la definición del sentimiento de sí (operativa retroactivamente en la esfera orgánica del animal): El Sí mismo es ideal (ideell), sin estar derramado o sumido en la materialidad, sino que sólo dentro de ella es activo y está presente (präsent), a la vez que allí se siente [y encuentra: findend] a sí dentro de sí mismo. Este ser puntual (Dieses Punktuelle) y, sin embargo, infinitamente determinable, que en su simplicidad sigue sin estar enturbiado al tenerse a sí mismo por objeto, es el sujeto en cuanto Sí mismo de sí mismo, en cuanto autosentimiento (das Subjekt als Selbst-Selbst, als Selbstgefühl). (ib.; repárese en la cláusula que he subrayado: sólo dentro de la materialidad es el Sí mismo ideal, y sólo en ella tiene el sentimiento de ser sí mismo). En el parágrafo siguiente, se enumeran los atributos esenciales de éste: ser semoviente, tener voz, calor propio e intususcepción, pero ser ante todo sentimiento, individualidad que en la propia determinidad es inmediatamente individualidad universal, que se mantiene y conserva simplemente cabe sí: es la idealidad existente del estar-determinado (Enz. § 351; TWA 9, 432).

Pero, a la postre, y como un sombrío omen que, partiendo de la esfera científico-natural, se extenderá por la Filosofía del espíritu (y no sólo por la dedicada al espíritu subjetivo), Hegel ha der reconocer el carácter mortal del sentimiento de sí, en cuanto expresión antitética: El organismo 
se halla entonces en las formas contrapuestas del ser y del sí mismo, mientras que el Sí mismo es justamente aquello para el cual él mismo es lo negativo de sí (Enz. § 371, Zus.; TWA 9, 521). En esa contradicción del organismo animal, manifiesta primero en la enfermedad, el individuo acaba sucumbiendo, aun cuando el género subsista y se reproduzca. Desde el punto de vista lógico, la contradicción consiste en que la universalidad, para ser concreta (y no meramente abstracta, como en el género), ha de ser individual y tener, por consiguiente, una existencia finita, en la cual su actividad se ha embotado y osificado, convirtiéndose la vida de este modo en una habituación (Gewohnheit) carente de proceso, así que el individuo se mata a sí mismo desde sí mismo (es sich so aus sich selbst tötet) (Enz. § 375, Zus.; TWA 9, 535). Aquí aparece pues -diríamos, avant la lettre- la noción en torno a la cual gira este trabajo.

Por otra parte, cabría preguntarse si esta muerte por pacífica elanguescentia es solamente animal (y por ende, propia del hombre en su respecto animal), o si esta carencia de procesualidad, y por tanto de conflictividad, no puede ser provocada (y con violencia) también en el ámbito propiamente espiritual, a fin de convertir al ser humano individual en un animal gregario: una contradicción más alta que la del sentimiento de ser sí mismo (porque, hasta ahora, Hegel ha hablado sólo de individuos). En este caso, se trataría -trastornando el orden enciclopédico y volviendo así a una locura más virulenta que la Verrücktheit tratada- de una autoconciencia que se sabe a sí misma como siendo una con un ser (Wesen) colectivo, pero que, ante una sensación insuperable de miedo o terror, se resigna a dejar de ser consciente, para convertirse en un animal con un número: ya sea de identificación nacional, o de exclusión y expulsión de la ciudadanía estatal, dentro de la propia nación. Es decir, y aunque ello signifique adelantarse un tanto a la conclusión final: desde un punto de vista político, habría que preguntarse, en el primer caso, hasta qué punto es el ciudadano individual absolutamente adecuado para la Patria como unidad de destino en lo universal; la contestación es sencilla: sólo cuando aquél da la vida por ésta (como si dijéramos: el buen ciudadano es el que está ya muerto -a título póstumo, como héroe desconocido- o bien el que se lanza libre y voluntariamente a la muerte; cf. Duque 2021, pp. 174176). En un nivel menos perentorio, propio del mundo griego, daría lo mismo, pero en axiológica inversión: un mal ciudadano era condenado al ostracismo, convirtiéndose así en un apátrida que podía ser muerto impunemente por cualquiera (es el caso de Layo, en Edipo rey).

Claro está, añadiría yo por mi cuenta: esa respuesta -correcta- se sigue de una pregunta mal planteada, y ello por los dos extremos: o bien la Patria es una vacua abstracción -creada pro domo para garantizar a diversos grupos su medro y prosperidad-, y entonces el individuo ha de negarse con razón a verse nivelado por su parte como mera abstracción, como uno de tantos; o bien la Patria es concretamente el ser más grande que exista sobre la tierra, ya se entienda como un ser viviente -tal el caso de los griegos: el hombre como zôōn- o como un constructo: un dios artificial -como en Hobbes-. Pero en ese caso, el ciudadano tendría que dar su vida sólo si se considerase a sí mismo como un miembro más de ese zôōn mégiston, o como un ser libre que libremente decide dejar de serlo por miedo a una muerte violenta, autolimitándose no menos libremente a obedecer órdenes de una Instancia superior irresistible: el Leviatán. Y en el segundo caso (producido comúnmente en y por el mismo régimen que el primero, por más que sus ideólogos prefieran hablar de Behemot), el otro habitante del Estado, por ser otro (poseído 
como está $a b$ ovo por el genius de una madre que, por su sangre, jamás podrá integrarse en la Madre Patria común), es visto como un ser infecto e infeccioso que contamina la salud y pureza de los habitantes de pleno derecho por características, paradójicamente, de tipo animal -como en el nacionalsocialismo racial-, o a lo sumo de carácter psíquico, sensu hegeliano: alguien que tiene ciertamente sentimiento de sí pero no alcanza a ser yo, y menos a formar parte del Nosotros. En fin, como se ve, aparte del hegeliano hay también otros ejemplos de esa muerte por conversión en cosa inerte, estando más bien la habituación a cargo del respecto activo (aunque haya casos, inducidos, de resultados más cercanos al ejemplo hegeliano: piénsese en las múltiples variedades de apartheid: desde la creación de reservas y campos de refugiados y en la acumulación de ghettos y banlieux en el extrarradio de las grandes ciudades, como Ciudad México o Buenos Aires, a fin de evitar el contagio con las personas decentes, afectadas de aporofobia).

Y es que no sólo se puede ascender en la escala enciclopédica, yendo desde el organismo animal y la vida sentiente hasta el sentimiento de sí y una lenta y casi inconsciente habituación (al cabo, mortal, a menos que se interrumpa esa identificación de la habitación con su habitante mediante oportunas innovaciones, creando ex ovo nuevas habitudes; o de forma más expeditiva, como veremos en Hegel, mediante una buena guerra que renueve un sentimiento de identidad nacional ya mortecino: matar o ser muerto para no morir de tedio). Son, ésas, formas políticas, debidas si se quiere al genius malvado (selbstsüchtig: ansioso de ser exclusiva y excluyentemente Símismo) que inmora en grupos, facciones y aun naciones enteras que utilizan el entendimiento o sano sentido común para convertirse ellos mismos en bestias sin saberlo, al pretender convertir a sabiendas en bestias a otros seres humanos. Hay una manera demoníaca de obedecer al daímon: querer ser libre y estar en propia casa, no para convivir dentro de lo otro de sí -que no deja de ser eo ipso él mismo Sí mismo, sino por expulsar de esa casa al otro de sí mismo. Volveré al final sobre el tema.

Tras este recorrido por la selva oscura de sensaciones y sentimientos encontrados, apenas controlables por un Selbst demasiado empapado de naturaleza, podemos arribar en fin al hábito, como superación del sentimiento de sí. Mientras que, sumidos en las particularidades de los distintos sentimientos (de lo más bajo: el apetito animal, a lo más complejo: las pasiones y deseos propiamente humanos), nuestro Sí mismo está en ellas, sin llegar a tenerlas y dominarlas, en cambio la reflexión del Sí sobre sí mismo niega (o mejor: reniega de) la supuesta emotiva independencia virulenta. Y sobre esa idealización de los sentimientos (en un sentido, desde luego, bien distinto al habitual) se comba el Sí sobre sí mismo, y llega a ser lo que él ya era en sí o para nosotros: referencia simple de la idealidad a sí misma (Enz. § 409; TWA 10, 182). Por cierto, Hegel no indica en este punto a qué se debe o más bien qué o quién impulsa al Selbst a tomar una decisión que, a tenor de las limitaciones del sentimiento de sí, éste era incapaz de realizar. Y no sólo eso: en la edición enciclopédica, el filósofo lleva extremosamente ese reniego hasta la propia corporalidad, con la cual -dice- el alma en cuanto habituación aquí rompe (bricht) (ib.; 10, 183). Ahora bien, esa ruptura sólo puede entenderse como una inversión de dominación; de lo contrario, no se entendería que, al final de la Antropología en la Vereinsausgabe se diga que: en el ahora logrado nivel evolutivo del alma [...] el sí mismo se ha puesto dentro 
del estar-ahí de ésta, se haya realizado dentro de su corporalidad (Leiblichkeit) y puesto el ser dentro de sí mismo. (Enz. § 412, Zus.; TWA 198). Por eso, y de un modo más circunspecto, en la lección de 1827/28 se nos dice: En la sensación particular puesta dentro de él [del sí mismo], la inmediatez de aquélla, es decir la corporalidad del alma, viene asumida (aufgehoben), obteniendo así forma de universalidad (VPhsG; G.W. 25.2: 725). Y también se nos indica cómo sucede esto (pero no por qué el almasalta del autosentimiento a una generalidad reflexiva, o sea, al hábito): la conformación (Einbildung: sería más exacto verter in-formación) de esas sensaciones según esta corporalidad del sí mismo (el cual es ya en sí el género de las mismas) aparece por tanto como una repetición. (ib.). Repetición pues, genérica y general (propia lógicamente de la Allheit, es decir, de una universalidad solamente formal, nur formelle; cf. el correspondiente locus lógico, e.d. el juicio de reflexión: la particularidad, ampliada a universalidad, o sea, determinada por la singularidad del sujeto, es la generalidad [Allheit] (la cualidad formal de tener algo en común [Gemeinschaftlichkeit], la habitual [gewöhnliche] universalidad-de-reflexión) (Enz. § 175; TWA 8, 326). Por esa cualidad formal de conversión de lo especial y particular en algo vulgar, ordinario (gemein), al alma dispuesta a habituación le da igual el contenido de esas sensaciones. Lo único importante es el ejercicio de esa formalidad, en virtud de la cual todas esas variadas sensaciones y sentimientos, una vez trabajadas y, por así decir, sedimentadas, se convierten en una segunda naturaleza (cf. Ranchio 2014, Khurana 2013 y Testa 2018). Al respecto, es preciso añadir que el hábito no es esta otra naturaleza, sino el que la produce. Es verdad que, en este contexto, se afirma que la habituación ha sido denominada [por Aristóteles, F.D.] como una segunda naturaleza, y con razón: Enz. § 410, Anm.TWA 10, 184; pero, como la referencia -aun implícitadeja en claro, se trata de una metonimia, a saber: de la habituación en cuanto producto rutinario, no en cuanto aprendizaje -al principio- consciente. Como tal, el hábito se comporta -en el ámbito de la lógica subjetiva- como un mecanismo (así también, la naturaleza en general, de suyo, no es ni mucho menos mecánica, sino pura extrinsecación recíproca, un continuo estar-fuera-de-sí; muy al contrario, es la Mecánica la que, pro domo, la trata y estudia como si fuera tal). El propio Hegel ofrece como ejemplo de mecanismo esa habituación:

Igual que el mecanismo material, también el espiritual consiste en que los términos respectados dentro del espíritu siguen siendo exteriores entre sí, y exteriores a aquél. Una manera mecánica de representación, una memoria mecánica, la habituación (Gewohnheit), una manera mecánica de obrar, significan que falta la peculiar penetración y presencia de espíritu en aquello que éste aprehende o hace. Aunque el mecanismo del espíritu, sea teórico o práctico, no pueda tener lugar sin la autoactividad de éste, no sin impulso y conciencia, falta allí, sin embargo, la libertad de la individualidad; $y$ al hecho de que ella no aparezca allí se debe que tal hacer aparezca como un hacer meramente exterior (WdL. G.W. 12, 133).

La segunda parte de este texto no deja de suscitar cierta inquietud. Si es cierto que sin autoactividad, impulso y conciencia por parte del espíritu, no puede activarse este mecanismo espiritual, ello significa que el espíritu se sume consciente y voluntariamente en la inconsciencia mecánica, en esa segunda naturaleza de los sentimientos controlados y nivelados. Pero, ¿a qué puede deberse ese olvido de sí por parte del propio Sí mismo, que tanto ha extrañado a 
Catherine Malabou: El hombre hegeliano es ante todo un hombre de hábitos, lo cual significa, paradójicamente, que es un sujeto evanescente. [...] Cuando el hombre hace su entrada en la narrativa especulativa, lo hace bajo la forma de un adiós (Malabou 2005, p. 75). Quizá no haya motivos de extrañarse por el hecho de esta autodesaparición del sujeto. Al fin y al cabo, también al final del Prólogo de la Fenomenología queda sentenciada la irrelevancia del individuo en la Era Moderna (cf. Phä. G.W. 9: 49). La razón profunda de ese voluntario olvido de sí mismo (de olvido del Sí mismo, que, como sabemos, se esforzaba por dominar su propia naturaleza animal) se ofrece cuando Hegel trata en la obra citada de La formación (Bildung) y su propio reino de realidad efectiva: Ahora bien, la renuncia [por parte de la autoconciencia] de su serpara-sí es ya el engendramiento (Erzeugung) de la realidad efectiva; y, en consecuencia, es en virtud de esa renuncia como se apodera inmediamente de ella. (ib. 9: 267). Recuérdese, en este punto, lo dicho al principio respecto a la disparidad en general de la ordenación enciclopédica y el orden habitual del tiempo: esa doble domesticación es propia de la Modernidad, e implica desde luego la posesión plena de razón y voluntad, empleadas de consuno para impregnar el cuerpo viviente (incluyendo también, como veremos, al cuerpo social), y hacer de él y de su entorno instrumento preconsciente del espíritu. Sólo a través del hábito, que es siempre en su inicio inducido y provocado, es posible la libertad, tanto individual como institucional. Esto, que nosotros adelantamos ahora para comprender la génesis del hábito, queda explicitado a sensu contrario más adelante, en la Fenomenología enciclopédica. Sin decirlo explícitamente, parece claro al respecto que, de atenerse a la letra de Hegel, el hombre de la antigüedad no podía conocer la habituación (porque la pertenencia inmediata a una tribu, un clan o una pólis no precisa de ejercicio ni de repetición alguna: se da y se hereda como algo evidente). Lo mismo sucede con respecto a la libertad antigua, que se alza como renombre propio (el pródromo del espíritu) contra la primera naturaleza: su propia condición animal, interiorizada empero como naturaleza humana inmediata, a saber: el apetito de conservarse en vida y de reproducirse. Esa libertad primera, todavía incipiente, sólo se logra mediante la lucha por el reconocimiento de las autoconciencias enfrentadas, en la cual se prueba por vez primera la capacidad para la libertad (Enz. $\S 431$, Zus.; TWA 10, 220). Solamente sobre este mutuo reconocimiento ético es posible establecer un mecanismo de habituación que permita un mayor grado de innovación sobre la segunda naturaleza, o sea: sobre la esfera ética sociopolítica, considerada mecánicamente.

En la eticidad moderna, pues, el hábito acaba revelándose como una argucia, como la astucia que la razón ejerce sobre y contra ella misma, para poder controlar los dos extremos domesticados: el Sí mismo -en cuanto miembro de la familia, todavía demasiado natural- y la segunda naturaleza ética (patente en la sociedad civil, que funciona en efecto de manera mecánica: lo propio del maquinismo industrial). Es esa habituación a la eticidad la que reflexiona sobre esas bases, hasta su encarnamiento en el individuo, dentro de la esfera antropológica. Aquí, el individuo prepara el camino sans le savoir para la irrupción de esferas y actividades superiores y más complejas, pero que ya están operando secretamente en el cuerpo y el alma individuales. Es el individuo el que domestica a la segunda naturaleza al domesticarse a sí mismo en su aparato sensorial, para que luego él mismo (ya como burgués o ciudadano) pueda ejercer en general, sobre esa base dominada, actividades más complejas. Hegel pone como ejemplos la posición erecta del cuerpo humano (añadiendo una precisión que, sin el caveat anterior, no tendría al parecer sentido: el hombre se pone en pie solamente porque él quiere y mientras él quiera, y sólo durante el 
tiempo en que él lo quiera, aunque sin conciencia (bewusstlos). (Enz. § 410, Anm.; TWA 10, 186). El hombre prosigue sus hábitos con conciencia del carácter inconsciente de éstos: lo normal es que él continúe así mientras éstos le sirvan. Y es que, en suma, el hábito es la normalización de la norma, la interiorización de reglas y mandatos a los que él, por lo general, asiente. Pero no siempre, como se verá al punto. Mientras tanto, el ejemplo de la posición erecta, tan banal, puede extenderse también, por ejemplo, a la visión (no en el mero sentido del juego entre visión y vista, pues esa acción, aun devenida inconsciente, agrupa en un solo acto tanto la sensación -ver algo-, la conciencia -parar mientes en algo-, la intuición -atender intencionalmente- y hasta el entendimiento: también hay reglas para aprender a ver). Es más, la propia acción de pensar precisa, para convertirse en hábito, de frecuencia y repetición. Y como un desmentido de lo dicho anteriormente sobre la ruptura del alma respecto a su propio cuerpo, añade algo con lo que de seguro estarán de acuerdo los lectores del filósofo, a saber: Incluso esta inmediatez del estar cabe sí pensante contiene corporalidad (la falta de costumbre y una larga prosecución del pensar provoca dolor de cabeza) (Enz. § 410, Anm.; TWA 10, 186).

Como cabe apreciar, el tema de la habituación está desbordando de este modo los estrechos márgenes de la Antropología, hasta el punto de que Hegel considera que el hábito constituye la existencia misma del Yo pensante consciente de sí: Sólo por esta habituación existo (existiere) Yo como ser pensante para mí. No es extraño, pues, que en este mismo contexto podamos leer: La forma de la habituación engloba todos los tipos y niveles de la actividad del espíritu (Enz. $\S$ 410, Anm.; TWA 10, 186).

Sin embargo, la inmersión consciente del espíritu como alma carnal tiene también sus peligros, como se apuntó hace un momento. Algo libremente ejercido y continuado acaba por convertirse en cosa necesaria; realizada, diríamos, a ciegas. Para poder dominar todos los problemas del tráfico de vehículos prestando atención a toda suerte de posibles obstáculos que puedan presentarse, es preciso realizar maniobras de manera automática, desde el arranque hasta el cambio de marcha o la acción de frenar. Pero esa necesidad inconsciente puede llevar a la inconsciencia (en el sentido habitual del término), de manera que esa habituación haga del hombre, señala Hegel: su esclavo, y no por una naturaleza inmediata, primera [recuérdese la lucha por el reconocimiento, F.D.], sino en todo caso por algo que sigue siendo naturaleza, en forma de una ley aceptada de manera inmediata y puesta más bien por el alma: una segunda naturaleza. (Enz. § 410, Zus.; TWA 10, 189). Al fin, la rutina mecánica puede hacer olvidar quién manda en ella, y para qué lo hace. Y el espíritu del individuo se contagia por así decir de esos movimientos habituales en los que se encarna su actividad. El hábito es, como estamos viendo, la contradicción por excelencia: naturâ anceps. Al mismo tiempo y en el mismo respecto, él es: la existencia de toda espiritualidad en el sujeto individual. Pero, precisamente por ser ex-sistencia, es decir: manifestación fenoménica de la esencia (y ésta es, no lo olvidemos, abstracta y genérica) está destinado al desgaste y, en definitiva, a la muerte (no sólo de un hábito concreto, sino del individuo). Y asílo que encontramos al final de la Filosofía de la naturaleza como destino del individuo, retorna ahora, espiritualizado, al final de la Antropología: es el hábito de vivir lo que nos lleva a la muerte, o dicho de un modo enteramente abstracto, es la muerte misma (Enz. § 410, Anm.; TWA 10, 187). Es más, que se trate por lo común de una ley aceptada, como citamos hace poco, permite prever (como si no fuera 
suficiente con las continuas alusiones que se han venido realizando) que esa muerte puede darse también, y, sobre todo, en el ámbito social. Y así, hacia el final de los parágrafos introductorios de la Eticidad, nos encontramos con que su lugar objetivamente-espiritual, o mejor: el sitio en el que se mueve esa vida ética, es justamente el concretum histórico-social de una serie de hábitos entrelazados, constituyendo así la costumbre (Sitte), entendida como segunda naturaleza [...] el espíritu viviente y presente como un mundo: la sustancia de la voluntad que, así, hay que considerar por vez primera como espíritu (Rechtsphil. § 151; TWA 7, 301).

¿No es sorprendente? La cosa más banal y, justamente, habitual del mundo constituye la sustancia de la voluntad espiritual: la base de todo el desarrollo ético: familiar, social y político. Pero es sólo la sustancia. Y ésta pertenece al ámbito de la lógica de la esencia, transida -como hemos visto- de necesidad ciega. Por eso, repetidamente (algo a lo que ya nos vamos habituando) encontramos aquí también, en ese punto más alto del espíritu objetivo, a la muerte (ahora se habla del hombre, no del individuo animal ni del alma carnal):

El hombre muere también por habituación, esto es, cuando se ha acostumbrado por completo a la vida, cuando se ha embotado espiritual y físicamente y ha desaparecido la oposición entre la conciencia subjetiva y la actividad espiritual; pues activo lo es el hombre tan sólo cuando, por no haber alcanzado algo, quiere producirse (produzieren) a sí mismo en lo referente a ello, prevaleciendo sobre ello. Pedro cuando aquello se ha consumado (vollbracht), desaparecen actividad y vitalidad, y la falta de interés que entra entonces es la muerte, espiritual o física. (Zus.; 7, 302).

La razón aducida por Hegel para explicar la irrupción de esa muerte, también ella anceps, es ciertamente metafísica (en el sentido habitual del término), y para algnos puede resultar por ello no demasiado convincente. En efecto, olvidando que la naturaleza es, como ya se apuntó, de suyo extrinsecaciónrecíproca: un estar-fuera-de-sí (e.d., no tener más bien ningún Sí mismo por sí misma), y que el juego de sus formas no es sólo una contingencia dislocada y desenfrenada, sino que a cada una de sus figuras le falta de por sí el concepto de ella misma (Enz. § 248, Anm.; TWA 9, 28; cf. también § 247); olvidando todo ello, digo, afirma en otro lugar que

...la evolución [o desarrollo: Entwicklung], que en la naturaleza es un tranquilo brotar (ein ruhiges Hervorgehen), es en el espíritu una dura lucha infinita contra sí mismo. Lo que el espíritu quiere es alcanzar su propio concepto; pero él mismo se lo encubre (verdeckt), orgullo y lleno de gozo en esta alienación de sí mismo. (Vorl.Phil.Gesch.; Einl.; TWA 12, 76; cf. también Enz. § 246, Zus.)

Todas las revoluciones que acontecen en las ciencias al igual que en la historia mundial se deben tan sólo a que el espíritu, entonces, para comprenderse y captarse a sí mismo, para poseerse, ha cambiado sus categorías, comprehendiéndose de un modo más verdadero, profundo, íntimo y siendo uno consigo mismo (TWA 9, 20). 
Bajando un poco más a tierra y a la arena política, parece claro, tras esta tenaz persecución del concepto de hábito, que éste sólo puede evitar la muerte (y de paso, la de individuos, grupos y hasta imperios enteros), si se cambia a tiempo de hábito, cuando éste da señales de cansancio (también así se habla al respecto de cansancio de materiales). Si es verdad que el progreso en la conciencia de la libertad (en que consiste, según Hegel, el curso entero de la historia mundial) sólo se logra mediante la creación, modificación y abandono de hábitos para ensayar otros nuevos. Y ello implica, desde mejoras puntuales y parciales de una forma histórica de vida, hasta grandes catástrofes, anunciadas mediante la perentoria necesidad de un cambio de paradigmas (como en el momento actual, sin ir más lejos), seguida por épocas muertas (con el hábito triunfa sobre el conflicto). O, dicho de otro modo: el hábito surge de la estabilización de conflictos. O, mejor dicho: el hábito no es sino la estabilización -siempre precaria- del conflicto.

Cabe admitir esto. También podemos leerlo, p.e., en Hartmann (2003, p. 187):

Los hábitos sostienen un mundo que sigue siendo igual hasta ulterior noticia. [...] En este sentido, los hábitos son atemáticos hasta la irrupción de una crisis [...] No es que el hábito busque esas crisis, sino que son ellas las que chocan con los hábitos, de modo que éstos han de ser reelaborados creativamente.

Sólo que, en otros momentos, se adelantan algunas reflexiones un tanto inquietantes. Desde luego, parece obvio que hay que evitar el conformismo generalizado (si es que alguna vez se ha dado tal cosa), como si uno se dijera: Yo soy esto, tal es mi manera general de ser [...] lo que yo soy es la totalidad de mis hábitos; no puedo hacer otra cosa, soy justamente así (Vorl.PhG. 13, 124). Ahora bien, esa confesión - plácida o resignada- de neutra conformidad con el sistema, sin otro baremo espiritual, puede favorecer al bien o al mal de un individuo o de una comunidad, por más que esos hábitos broten tranquilamente unos de otros, con toda naturalidad. Si se me permite citar dos extremos, ese nihilismo búdico puede ser ilustrado tanto con la actitud de mucha gente decente durante el nacionalsocialismo alemán y los años de plomo del franquismo, como también con el desparpajo de la dibu Jessica Parker, cuando confiesa: Yo no soy mala: es que me han dibujado así. (En: Pero, ¿quién engañó a Roger Rabbit?, el film de R. Zemekis, de 1988). Por eso, poco después del pasaje del Curso de 1827/28, recién citado, pone Hegel en cambio de relieve el polo opuesto: el hábito como Grundlage o basamento de la libertad. En efecto: La definición (Bestimmung) esencial del hábito es que él es aquello por cuyo medio ese hombre queda liberado de las sensaciones por las que él mismo se ve afectado (Vorl.PhG. 13, 125).

Bien está. Quizá por ello afirme Hegel (pasando ya resueltamente al ámbito social): El pueblo carente de actividad (thatlose) carece de tacha, está envuelto dentro de la universalidad objetiva, ética, y allí disuelto [...] entrando así en una relación de exterioridad frente a su propia naturaleza, y en el mecanismo ( $W d L$. G.W. 12, 142). Puede que el filósofo se esté refiriendo aquí al pueblo en general, pues de lo contrario cabría preguntar a quién beneficia o perjudica esa falta de actividad (que, como hemos visto, equivale a la muerte espiritual). Y es que, en un sentido más habitual, ya sabemos lo que piensa Hegel del pueblo: Los muchos, entendidos como singulares, que es lo que se entiende gustosamente por pueblo, son ciertamente un 'estar juntos' (Zusammen), pero 
sólo como la multitud: una masa amorfa, cuyo movimiento y obrar no sería por consiguiente sino algo elemental [elementarisch: como los elementos naturales, F.D.], carente de razón y temible (Rechtsphil. § 303, Anm.; TWA 7, 473). Lo cual no deja de ser curioso, porque incluso para que un individuo se ponga de pie y camine es preciso tener voluntad, y duradera: algo que se le niega al pueblo: En la medida en que con esa palabra se mienta una parte determinada de los miembros de un Estado, lo que dicha parte expresa es que ella no sabe lo que quiere (der nicht weiss, was er will) (Rechtsphil. § 301, Anm.; TWA 7, 469).

De esto cabría deducir que ese pueblo no debe de ser el habitual, sometido -como se vio al principio- al entendimiento o buen sentido común. Y no debe de serlo porque, o bien la costumbre ha acabado por suprimir todo ejercicio de aprendizaje y habituación (su hábito es no tener ya hábitos, en plural, diversos y aun contrapuestos), así que esa masa amorfa no sabe lo que quiere hasta que alguien entendido le diga qué es lo que él quería sin saberlo; o bien es temible porque, cuando lo hace, es tan imprevisto en sus movimientos y tan irracional y desenfrenado como los elementos de la naturaleza. Con lo cual, no es difícil caer en la cuenta de que ese pueblo en bruto reúne antitéticamente dentro de sí los dos extremos contrapuestos propios justamente de la naturaleza. Sólo que ello no puede achacarse a la primera naturaleza, sino a la segunda. Ese pueblo, o más bien su residuo inorgánico, es la plebe (Pöbel), que también Kant tacha de ignobile vulgus, por no querer atenerse al entendimiento (Anthrop. §10; Ak. VII, 145).

¿Es posible domesticar (reciclar, diríamos hoy) ese resto? Parece que no, aunque al menos pueda ser hasta cierto punto controlado por la sociedad civil con las corporaciones, y por el Estado con la policía. De esta manera se le permite a la parte obediente del pueblo, bien habituada por esas fuerzas del orden (social y político), poder pasear en horas intempestivas, que de lo contrario estarían en manos de la plebe. Y es que, mediante un elogio fuera de lo común, vemos ahora que el hábito no es sólo la existencia del individuo pensante, sino la entera existencia del hombre. Y de ello se habla en un parágrafo dedicado a la convicción moral en el plano político, o sea: al patriotismo. ¿Qué es el patriotismo? Respuesta: es esencialmente la convicción que, en las condiciones y circunstancias habituales de la vida, se ha habituado a tener a la cosa pública [Gemeinwesen: la res publica; F.D.] por basamento y fin [de uno mismo] (Rechtsphil. § 268, Anm.; TWA 7, 413; subr. mío). Todo ello se debe a la costumbre (se entiende: a las buenas costumbres): La habituación llega a hacer invisible aquello en que descansa toda nuestra existencia. Y pone como ejemplo:

Va alguien de noche por la calle y no se le ocurre que eso podría suceder de otra manera, pues es esta habituación a la seguridad la que se ha convertido en otra naturaleza, sin parar mientes en que ello es, en primer lugar, efecto de determinadas instituciones [...] Hay gente que opina a menudo que la cohesión del Estado se debe a la violencia; pero aquello que lo sustenta es únicamente el sentimiento fundamental (Grundgefühl) del orden que todo el mundo tiene. (Rechtsphil. § 268, Anm.; Zus.; TWA 7, 414). 
He aquí, por fin, el hacedor e inductor de los hábitos (presumiblemente, no sólo de los sociales), a saber: las instituciones que inculcan en todo el mundo ese sentimiento que es más fuerte que el Selbstgefühl: el sentimiento de que, como se dice comúnmente en Alemania: debe haber orden (Ordnung muss sein). Las instituciones, social (corporaciones) y política (los poderes del Estado), generan el orden; éste viene interiorizado por los ciudadanos, que, a su vez y por medio de instituciones más básicas: el derecho común (o sea: el código civil y el penal) y la familia, descienden hasta grabarse, hasta encarnarse en la vitalidad cuasi animal del individuo.

¿Por qué medio se realiza esa formación del espíritu como alma y como Sí mismo? En primer lugar, por la educación: la formación (Bildung) [...] considera al hombre como natural, y le muestra el camino para renacer de nuevo (wiederzugebären), transformando su primera naturaleza en una segunda, espiritual, de modo que lo espiritual se convierta en él en hábito. (Rechtsphil. § 151 Z, S. 302). En segundo lugar, como ya se ha indicado, por las corporaciones, es decir, por instituciones sociales que moldean (formieren, diríamos, en cuanto inversión de la Bildung) al individuo, insertándolo -según sus méritos y necesidades- en una rama de la producción, en un estamento (cf. Rechtsphil. § 206; 7, 358). Sólo que, en este nivel, es la precisa la producción maquinista, propia del capitalismo industrial, la que genera con sus excesos una plebe no susceptible de ser encajada, in-formada dentro de un estamento particular, de modo que difícilmente puede convertir en hábito su precaria situación (diríamos que, por no poseer, ni siquiera posee su propia segunda naturaleza interiorizada: su fuerza de trabajo; quizá por ello se habla hoy con frecuencia, y con razón, del precariado).

¿Qué hacer, pues? Si dejamos a su suerte ( $\mathrm{y}$ al control policial) ese resto, el otro medio de adoctrinamiento de (buenos) hábitos sería la opinión pública, encargada precisamente de dar a conocer al pueblo, aunque de manera inorgánica, [...] qué es lo que él quiere y opina. (Rechtsphil. §316, Zus.; TWA 7, 483). Sólo que también ella es, empero, sospechosa, porque por un lado halaga hipócritamente la libertad subjetiva de los individuos: al menos, de aquellos que por entonces podían comprar un periódico, y de quienes, hoy, pueden ver la televisión, y sobre todo poner en marcha (formalmente, mecánica) su libre albedrío mediante las redes sociales. Y es que él creía que: Aquello que al presente ha de tener validez no lo tiene ya por la violencia sino, un poco, por hábito y costumbre (Gewohnheit und Sitte), pero más mediante razones y comprensión (Rechtsphil. §316, Zus.; TWA 7, 483; cf. también §§ 317-319). Esto último alude por cierto al respecto organicista, por el cual el Estado domestica al pueblo de arriba abajo (al contrario de la opinión pública). Por eso, mejor sería -piensa Hegel- que esa opinión fuera de veras pública (a través de la Gaceta Oficial del Estado), publicando al efecto las actas de sesiones del Parlamento; e incluso sería aún mejor que la gente asistiera personalmente a esas sesiones, de modo que, a través de la finura e ingenio de los diputados, el pueblo sano pudiera estar informado e ir refinando su modo de vivir y de pensar, dejando así paulatinamente de ser amorfo. Obviamente, estas buenas intenciones de Hegel no son válidas para el mundo actual.

En fin, esto es lo que da de sí la habituación como medio (inducido por las instituciones) de generación de pueblos e individuos, dentro de la constitución interna del Estado. En cuanto a la constitución externa, aquí será más bien el conflicto el que acabe convirtiéndose en una peligrosa habituación: a saber, y como ya se indicó en su momento, la de habituarse si es preciso 
(y en todo momento puede ser preciso) a dar la vida -y a quitarla- por la Patria. Y es aquí, en la guerra, donde finalmente habituación y conflicto intercambian sus funciones, y donde brilla en todo su esplendor la idealidad de las cosas mundanas, cuando el espíritu las tritura (recuérdese el zerquetschen de Enz. § 42, Zus.; TWA 8, 118). De hecho, de seguir a Hegel, la guerra es:

...la situación (Zustand) en la cual se toma en serio la vanidad de los bienes y cosas temporales; algo que, de lo contrario, suele tener forma de discursos edificantes; tal es por ende el momento en el que la idealidad de lo particular obtiene su derecho y se hace efectiva realidad.

Así que ésa era la idealidad, ahora convertida en efectiva realidad destructiva. La guerra sirve según Hegel justamente para deshabituar a la gente, sacándola de sus casillas, desquiciándola y haciéndola sentir otra manera bien poco habitual de vivir... y de morir.

¿Qué ha pasado aquí? Parece como si, para Hegel, fuera necesario y forzoso el conflicto: antes (la enfermedad, por el lado animal; la posesión y el desvarío, por el antropológico) y después (la violencia propia de la sociedad civil, a duras penas controlable, y la irremediable guerra entre Estados) del hábito. La habituación es pues sólo un término medio -eso sí, literalmente crucial-, en el cual y por el cual se constituye la existencia humana y se abre para el hombre la posibilidad de acceder a una libertad más alta. Pero esa mediación es precaria y ambivalente: promete vida y amenaza muerte. $\mathrm{Y}$ a eso no estábamos habituados. Ni lo estaremos, espero.

\section{Referencias}

Alexandre, C. $\left(1878^{18}\right)$ Dictionnaire Grec-Français [1830]. Hachette et Cie.

Aristóteles (1970) Ethica Nicomachea (= Eth. Nic.). (Ed. bil. de M. Araujo y J. Marías). I.E.P.

Aristóteles (1973) Metaphysica (Metaph.). (Ed. W. Jaeger). Clarendon Press.

Aristóteles (2017) Metafisica. (Trad., introd. e note di E. Berti) Ed. Laterza

Bernacer, J., y Murillo, J.I. (2014) La concepción aristotélica del hábito y su contribución a la neurociencia humana. Frontiers in Human Neuroscience, 8, 883 https://doi.org/10.3389/fnhum.2014.00883

Berti, E. (2015) L'intelletto attivo: una modesta proposta. Atti dell'Accademia Nazionale dei Lincei. CDXI 2014. Classe di Scienze Morali. Memorie, Serie IX, V. XXXV, pp. 59-71 https://www.unisalento. it>Sull'intelletto+agente.pdf

Diels, H., \& Kranz, W. (Eds.) (1992). Die Fragmente der Vorsokratiker (= DK). Weidmann.

Duque, F. (2020) Las figuras del miedo. Derivas de la carne, el demonio y el mundo. Abada.

Hegel, G.W.F. (1970). Grundlinien der Philosophie des Rechts (= Rechtsphil.). En Theorie Werkausgabe 7 (= TWA). Suhrkamp.

Hegel, G.W.F. Enzyklopädie der philosophischen Wissenschaften III [1830] (= Enz.). TWA 8, 9, 10.

Hegel, G.W.F. Vorlesungen über die Philosophie der Geschichte (= Vorl.Phil.Gesch.). TWA 12.

Hegel, G.W.F. $(1978,1981,1985)$ Wissenschaft der Logik $[1812,1813,1821]$ (= WdL). Gesammelte Werke (= G.W.). Meiner.

Hegel, G.W.F. (1980) Phänomenologie des Geistes [1807] (= Phä.). G.W. 9.

Hegel, G.W.F. (1994) Vorlesungen über die Philosophie des Geistes (Vorl.PhG). Berlin 1827-1828. En F. Hespe y B. Tuschling (Eds.), Ausgewählte Nachschriften und Manuskripte [vol.] 13. Meiner. 
Hegel, G.W.F. (2011) Vorlesungen über die Philosophie des subjektiven Geistes (Vorl.PhsubjG). Nachschriften zu dem Kolleg des Wintersemesters 1827/28 und sekundäre Überlieferung. Nachschrift Stolzenberg. Ed. Chr. Jo. Bauer, G.W. 25.2. Meiner.

Heidegger, M. (2015), Der Ursprung des Kunstwerkes (UKw). En Holzwege. Reclam.

Hartmann, M. (2003) Die Kreativität der Gewohnheit. Grundzüge einer pragmatistischen Demokratietheorie. Campus.

Kant, I. (1968) Idee zu einer allgemeinen Geschichte in weltbürgerlicher Absicht (=Idee). En Akademie Textausgabe (= Ak.) VIII. Walter de Gruyter.

Kant, I. (1797). Anthropologie in pragmatischer Hinsicht [1797] (= Anthr.). Ak. VII.

Khurana, Th. (2013) Life and Autonomy: Forms of Self-Determination in Kant and Hegel. En Th. Khurana (Ed.), The Freedom of Life. Hegelian Perspectives (pp. 155-193). August.

Khurana, Th. (2018) Politics of Second Nature: On the Democratic Dimension of Ethical Life. En P. Stekeler-Weithofer y B. Zabel (Eds.), Philosophie der Republik (pp. 422-436). Mohr Siebeck.

Leder, D. (1990) The Absent Body. University of Chicago Press.

Lumsden, S. (2012, publ. 2015) Habit, Sittlichkeit and Second Nature. Critical Horizons. Journal of Philosophy and Social Theory, 13(2), 220-243. https://doi.org/10.1558/crit.v13i2.220

Malabou, C. (2005) The Future of Hegel. Plasticity, Temporality and Dialectic. Routledge.

Novakovic, A. (2017) Hegel on Second Nature in Ethical Life. Cambridge University Press.

Platón (1970) Republica (= Rep.). L. IV. Ed. bil. de J.M. Pabón y M. Fernández Galiano. I.E.P.

Ranchio, F. (2014) Dimensionen der zweiten Natur. Hegels praktische Philosophie. [Tesi di Dottorato]. Università Ca' Foscari. Venecia

Tertuliano (1956) Treatise on the Incarnation (De carne Christi liber). Ed. Ernest Evans. S.P.C.K. https://es1lib. org/book/1211051/a51b79.

Testa, I. (2008) Selbstbewusstsein und zweite Natur. En K. Vieweg y W. Welsch (Eds.), Hegels Phänomenologie des Geistes. Ein Kooperativer Kommentar zu einem Schlüsselwerk der Moderne (pp. 286307). Suhrkamp.

Testa, I. (2009) Second Nature and Recognition: Hegel and the Social Space. En Critical Horizons. Journal of Philosophy and Social Theory, 10(3). 341-370 https://www.tandfonline.com/doi/abs/10.1558/crit. v10i3.341.

Testa, I. (2020) Embodied Cognition, Habit, and Natural Agency in Hegel's Anthropology. En M.F. Bykova y K.R.Westphal (Eds.), The Palgrave Hegel Handbook. Palgrave MacMillan.

Varela, F.J., Thompson, E., \& Rosch, E. (2017). The Embodied Mind, Revised Edition. Cognitive Science and Human Experience. The MIT Press.

\section{AUTOR}

Felix Duque. Catedrático Emérito de Filosofía. Fundador y ex-Coordinador del Máster Universitario: Filosofía de la Historia. Democracia y Orden Mundial. Doctor en Filosofía. Licenciado en

Psicología. Especialidad. Historia de la Filosofía Moderna (Idealismo Alemán), Hermenéutica (Heidegger), Filosofía de la Historia, Filosofía del Arte Contemporáneo (Arte público). 